\title{
How to Charge for Network Services - Flat-Rate or Usage-Based? ${ }^{\star}$
}

\author{
Jörn Altmann ${ }^{\mathrm{a}, \mathrm{b}}$ Karyen $\mathrm{Chu}^{\mathrm{c}}$ \\ ${ }^{a}$ Electrical Engineering and Computer Science, University of California, Berkeley \\ ${ }^{\mathrm{b}}$ Internet and Mobile Systems Lab, Hewlett-Packard Laboratories \\ 19420 Homestead Road, MS 43UF, Cupertino, CA 95014, USA \\ ${ }^{\mathrm{c}}$ Department of Economics, University of California, Berkeley \\ 549 Evans Hall, Berkeley, CA 94720-3880, USA
}

\begin{abstract}
Currently, the Internet service provider market offers two different types of pricing plans. In the USA, the predominant pricing plan is a flat-rate plan. In Europe and Asia, the predominant one is a per-minute pricing plan. Enrolled in such a pricing plan, users have to pay for the connect time to the Internet. Although Internet Service Providers (ISPs) have competed heavily for users in these last few years, they only have focused on trying to offer the lowest price within such pricing plans. A potentially more profitable and sustainable method of doing business would be for ISPs to differentiate themselves by offering more customized pricing plans for certain user groups. An important question then is whether a pricing plan exists that is attractive to users, but also allows ISPs to build a sustainable business. Based on empirical results of the INDEX project, we discuss a pricing plan for Internet access that appears to be appreciated by Internet users as well as by ISPs. This pricing plan combines the advantages of flat-rate pricing and usage-based pricing. Users will benefit by receiving unlimited access to a basic service with the choice of higher QoS whenever they demand. From the ISPs' perspective, such a pricing plan will help any ISP to focus on certain user groups and to reduce peak network load.
\end{abstract}

Key words: pricing plans, user demand for network services, experimental studies, quality of service, flat-rate vs. usage-based pricing

‡ This research was supported by grants from the National Science Foundation, Cisco Systems, SBC Communications, the California State MICRO Program, and the European Union's Fifth Framework Project M3I (Market-Managed Multiservice Internet - RTD No IST-1999-11429

Email addresses: jorn_altmann@hpl.hp.com (Jörn Altmann), kchu@econ. berkeley. edu (Karyen Chu).

Preprint submitted to Elsevier Science 9 March 2001 


\section{Introduction}

Although Internet Service Providers (ISPs) have heavily competed for users in these last few years, they have only focused on trying to offer the lowest price for Internet access. This could have been observed in Europe as well as in the USA. In Europe, where per-minute pricing is predominant, competition in the ISP market led to very low per-minute prices. In the USA, the competition between ISPs led to very low flat-rates for dial-up access service as well as for broadband access service. The only service differentiation in the USA broadband access market is the transmission rate. ISPs offer a selection of tiered services, which differ in the maximum access bandwidth. The user has to choose one of these services in the enrollment process.

Because of this situation, many smaller broadband access providers are finding it difficult to become profitable and many smaller dial-up ISPs have gone out of business. A potentially more profitable and sustainable method of doing business in the ISP market would be to focus on certain user groups by offering more attractive pricing plans. An eligible question then is whether a pricing plan exists that is attractive to users and also allows ISPs to build a sustainable business.

For the analysis presented in this paper, we use data gathered within the INternet Demand EXperiment project (INDEX). The data is used to estimate the magnitude of increase in usage under flat-rate unlimited-access pricing plans compared with usage-based pricing plans. We also show that users prefer flatrate pricing to usage-based pricing when the flat-rate charge is comparable to current unlimited access subscription prices charged by most major commercial ISPs. However, INDEX subjects take advantage of on-demand access to higher bandwidths when such access is available.

These findings suggest that ISPs may want to consider introducing a new type of pricing plan: one that provides flat-rated, unlimited access to basic service with the ability to access higher quality service on demand for which users are charged for their usage.

Within the paper, we discuss such a pricing plan for Internet access. This plan accords with users' preferences and meets the requirements of ISPs by combining the advantages of flat-rate pricing and usage-based pricing. Users benefit by the combination of flexibility and the flat-rated, always-on service. Using this pricing plan, ISPs will benefit since the plan will help addressing the needs of certain user groups and limiting the potential reduction in network performance due to congestion from over-usage.

The paper proceeds as follows: In the next section, we give an overview about existing pricing plans. The INDEX network architecture, the pricing experi- 
ments, and the subjects are described in section 3. In section 4, we estimate the magnitude of increase in usage under flat-rate pricing plans compared with usage-based pricing plans. In section 5, we present evidence that INDEX subjects, despite their heterogeneity, prefer flat-rate pricing to usage-based pricing when the flat-rate charge is comparable to current, unlimited-use subscription prices charged by most major commercial ISPs. In section 6, we explain that the INDEX subjects are willing to pay usage-based charges to access higher bandwidths on demand even after they have paid for unlimited access to a lower bandwidth. We close with a short discussion of our proposed new pricing plan in section 7 .

\section{$2 \quad$ Pricing Plans Offered}

The primary pricing plan currently offered by both dial-up and broadband Internet service providers in the USA is a flat-rate pricing plan. This plan offers unlimited access to the Internet backbone service for a flat monthly charge, which is typically approximately $\$ 22$ per month for dial-up Internet service and approximately $\$ 10$ to $\$ 200$ per month for broadband Internet service. In addition to this, the user has to pay for the access line to the Internet backbone. This is either the telephone line or the DSL line. The telephone line costs $\$ 15$ per month and the DSL line costs $\$ 40$ per month. Common to these flatrate pricing plans, users are only provided with access to a single bandwidth, without the ability to select a higher bandwidth on demand. Users who want access to higher bandwidths must pay a higher monthly fee for unlimited access to that higher bandwidth. For example, Pacific Bell currently offers unlimited DSL access at speed of $384 \mathrm{kbps}$ downstream and $128 \mathrm{kbps}$ upstream for $\$ 10$ per month (in addition to $\$ 40$ per month for the DSL line). Users who want access to a higher bandwidth must pay $\$ 199$ per month, giving them unlimited access to 1.5 mbps downstream and 384 kbps upstream.

In Europe, although flat-rate pricing plans exist, ISPs mainly offer per-minute pricing plans. These plans include free usage of some minutes. However, if users exceed the free minutes, users have to pay for their usage. The per-minute rates for Internet access service vary between 1 cent and 4 cents within Europe, independent of the access technology (telephone line or DSL line). The flatrate fees for Internet access are $\$ 20$ per month for dial-up service and $\$ 25$ per month for DSL service. In addition to this, the user has to pay for the telephone line (\$12 per month) and the DSL line (\$35 per month). While the access speed of dial-up service is limited to $64 \mathrm{kbps}$, DSL access speed is $128 \mathrm{kbps}$ upstream and up to $768 \mathrm{kbps}$ downstream.

Flat-rate pricing plans are economically inefficient. Users do not face the true marginal cost of usage, resulting in over-usage and potentially higher than 
socially optimal levels of infrastructure investment to meet the demand. The high levels of usage under flat-rate unlimited-access pricing plans have the potential to reduce the overall network performance under broadband access technologies. In addition, light users subsidize heavy users. Despite these inefficiencies, these plans predominate.

The disadvantage of pure per-minute pricing plans is that they do not motivate users to use and spend more time on the Internet. Per-minute pricing plans limit revenues from other sources such as retailing and advertisement. In addition to this, the reduced usage, in turn, inhibits the evolution of the Internet as a future multi-services network.

\section{INDEX}

The INternet Demand EXperiment project (INDEX), is a market experiment to measure demand for Internet access. User demand is analyzed as a function of quality of service (QoS), pricing plan, budget, and application. INDEX provides differentiated network services to its subjects, who pay for their usage of the network service.

\subsection{Architecture}

The INDEX access network provides IP service between the subjects' homes and the INDEX project network. The access speed is $128 \mathrm{kbps}$ upstream and 128 kbps downstream. INDEX installed an ISDN phone line at the subject's home and loaned a pre-configured Cisco 762 ISDN router to each subject. The lines coming from the subjects' homes are then multiplexed over ISDN primary rate lines at the Pacific Bell central office before they reach the INDEX project network (see Figure 1). In contrast to common industry practice, the whole network is heavily over-provisioned to make sure that none of the subjects experience deterioration of their selected quality level due to potential bottlenecks at the INDEX access network.

At the INDEX network, all IP packets go through either a Cisco 7507 router or a Cisco 7513 router. These routers forward all out-bound traffic to a set of Billing Gateways (BGWs) specifically designed to meter usage and adjust the service quality of traffic. All traffic generated by a given user is aggregated at the Billing Gateways, so that the quality for this bundle can then be controlled accordingly. The INDEX network is connected to the outside world through a Cisco 7200 router that is directly attached to the UC Berkeley $100 \mathrm{mbps}$ FDDI backbone. 


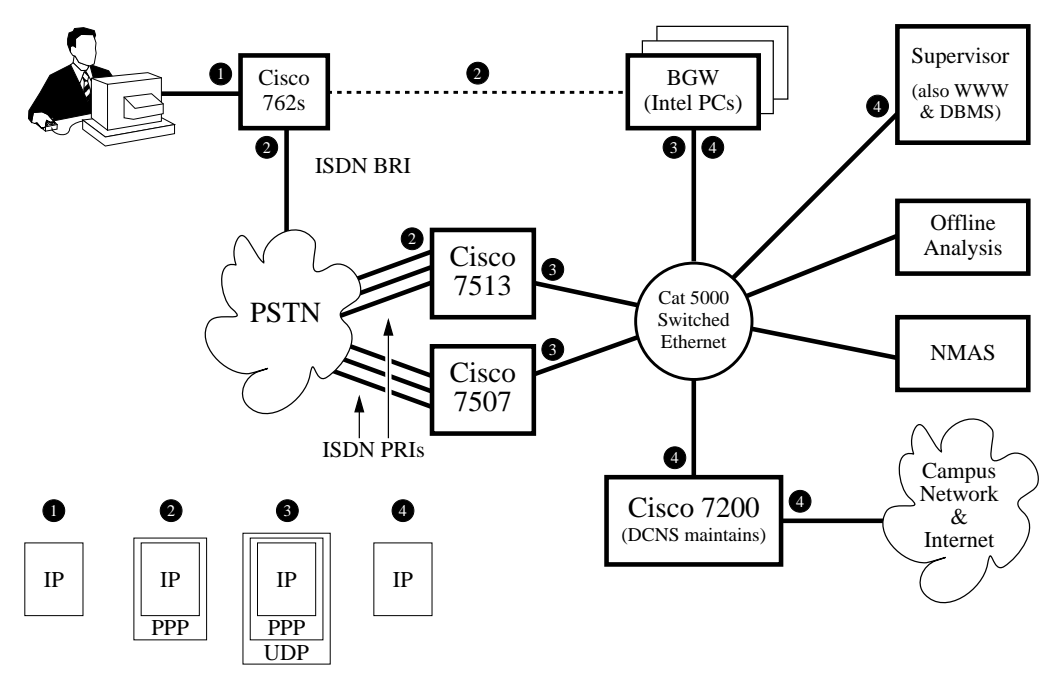

Fig. 1. INDEX Network

\subsection{Pricing Experiments}

The subjects choose their desired network service from a menu of QoS-price offerings, which actually consists of different bandwidth-price choices. The prices for the different QoS choices change every week. The menu of quality of service choices changes every six to ten weeks, defining an experiment. The subjects move through a sequence of Experiments, which are designed to measure user response to various quality-differentiated pricing plans. The approximately 70 subjects in this market experiment include faculty, staff, and students of the University of California at Berkeley.

\subsubsection{Minute Pricing Experiments}

During Minute Pricing experiments, INDEX subjects are charged per-minute rates for connecting to the Internet at each of five different bandwidths above $8 \mathrm{kbps}$. The $8 \mathrm{kbps}$ service is always available and priced at zero cent per minute in every experiment, giving INDEX subjects an alternative within the experiment to the campus modem pool which is also free of usage charges. The five bandwidths are $16 \mathrm{kbps}, 32 \mathrm{kbps}, 64 \mathrm{kbps}, 96 \mathrm{kbps}$, and $128 \mathrm{kbps}$. Subjects can select any of the offered bandwidths at any time and it is even possible to change bandwidths during an active session. There are two kind of Minute Pricing Experiments: the Symmetric Bandwidth experiment and the Asymmetric Bandwidth experiment. In the Symmetric Bandwidth experiment, the selected bandwidth is the same for upstream (out-bound) and downstream (in-bound) traffic. In the Asymmetric Bandwidth experiment, subjects can select different bandwidths for upstream and downstream traffic.

Both experiments run for seven weeks, which includes a free first week to allow 
subjects to experience the different bandwidths so that they would be able to make informed choices in the subsequent weeks. In the Symmetric Bandwidth experiment, prices change weekly in week two through six and daily in week seven. In the Asymmetric Bandwidth experiment, prices change weekly in week two through seven.

\subsubsection{Byte Pricing Experiment}

In the Byte Pricing experiment, INDEX subjects are given the choice of two bandwidths: $8 \mathrm{kbps}$, which is free of usage charges, and $128 \mathrm{kbps}$, whose usage is charged according to the number of bytes transmitted. The experiment runs for a total of seven weeks. Week one is again for free to allow subjects to learn about the volume of traffic that they generate. In weeks two through seven, the per-byte prices change every week.

\subsubsection{Minute-Byte Pricing Experiment}

This experiment was designed to understand individuals' preference in regard to their inclination towards per-minute or per-byte charges. The pricing plan is based on different combinations of per-minute and per-byte prices. The subjects are offered the choice of being charged exclusively on the basis of either minutes or bytes, or a combination of both. The user choices of selfselecting tariffs also reveal whether users behave rationally in an economic sense. Within each tariff, subjects can switch between six different bandwidths as in the Symmetric Bandwidth experiment.

\subsubsection{Flat-Rate Buy-Out Option Experiment}

In the Flat-Rate Buy-Out Option experiment, the INDEX subjects are charged per-minute rates for the five priced bandwidths. ${ }^{1}$ At the beginning of each week, subjects are given the opportunity to buy out any of the five bandwidths for the week by paying a fixed charge. Buying out a bandwidth, a subject gets unlimited access at the bought-out bandwidth for the week without having to pay the per-minute prices. Buying out a bandwidth also allows unlimited access at the remaining lower bandwidths. The fixed charge for buying out the highest bandwidth was randomly drawn. We refer to this fixed charge as the weekly buy-out price. The fixed charges for buying out any of the four lower bandwidths are a fraction of the randomly drawn weekly buy-out price. The subjects' buy-out decisions are binding for the rest of the week and cannot be changed. However, subjects who choose not to buy out the highest bandwidth

1 Data on this experiment are currently available for only 40 of the approximately 70 subjects. 


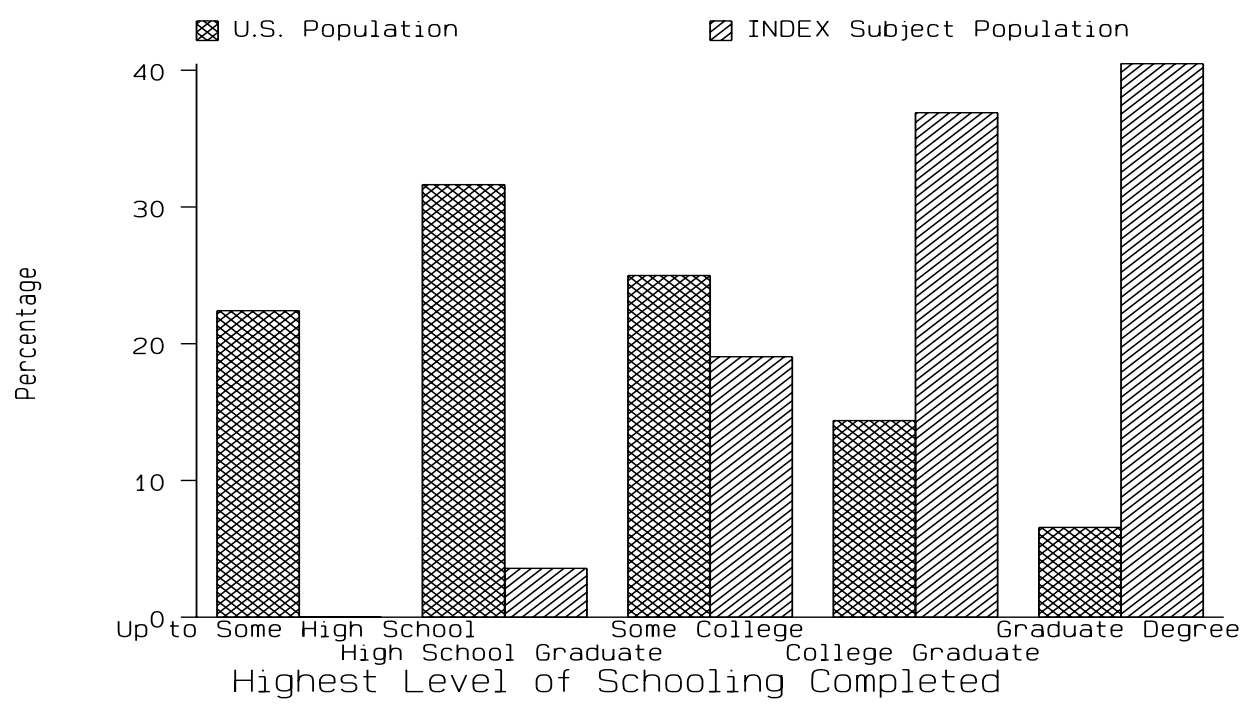

Fig. 2. Educational Achievements of INDEX Subjects and of the U.S. Population

are still able to use higher, non-bought-out bandwidths on demand during the week.

\subsection{Demographics of INDEX Subjects}

The age of INDEX subjects range from 20 years to 72 years, with a mean age of 35 years and a median age of 29 years. Due to their university affiliation, INDEX subjects have a higher level of education compared to the U.S. population. Figure 2 compares the educational achievement of the INDEX subject population with the educational achievement of the U.S. population. The data about the U.S. population is from the 1999 U.S. Census Bureau report [6]. While the level of education of the INDEX subjects and of the U.S. population differs significantly, the income distribution of both groups does not appear to differ significantly.

In addition to that, most INDEX subjects are experienced computer and Internet users: 90 percent of INDEX subjects already used the Internet three or more years ago, compared with 9 percent of the respondents in a populationrepresentative Nielsen survey. See Altmann et al, 1999b for more details [2].

\subsection{Heterogeneous Preferences of Subjects}

INDEX subjects have heterogeneous preferences. This heterogeneity of preferences is exhibited by large inter-subject variations, such as the variation in the weekly mean expenditure. 

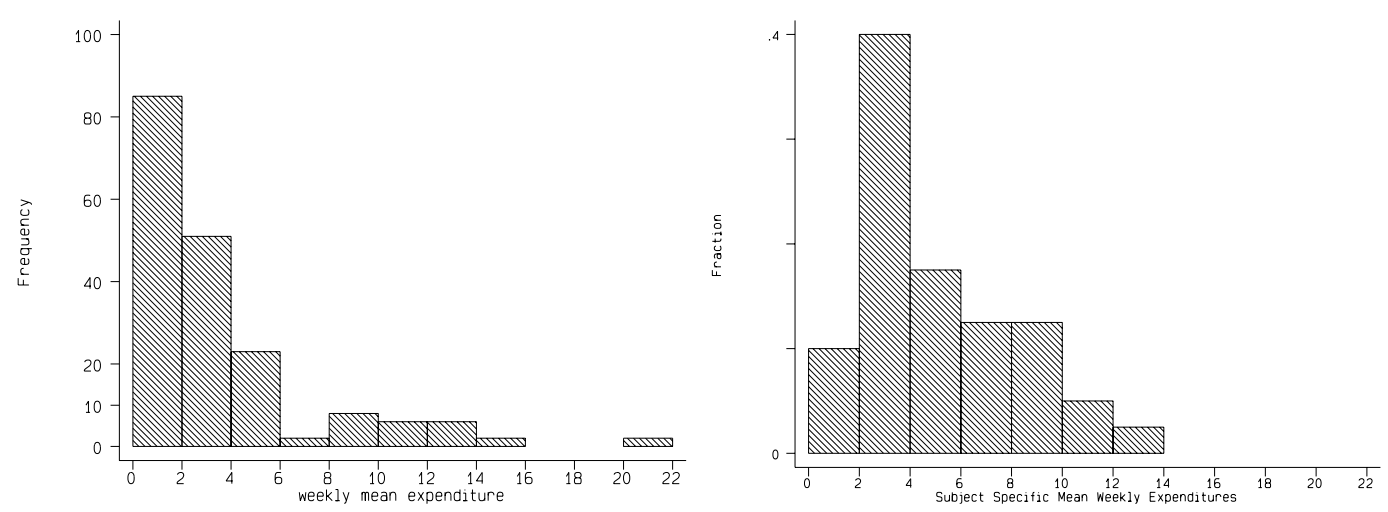

Fig. 3. Mean Weekly Expenditures; Left: Per-Minute and Per-Byte Pricing Experiments; Right: Flat-Rate Buy-Out Experiment

Figure 3 shows examples of inter-subject variations in weekly mean expenditure. The left graph depicts the subjects' mean weekly expenditures for three experiments: Symmetric Bandwidth experiment, Asymmetric Bandwidth experiment, and Byte Pricing experiment. The weekly expenditures in these three experiments range from a low of $\$ 0.20$ per week to a high of $\$ 21.23$ per week. A more detailed description can be found in Altmann et al 1999b [2]. The right graph of Figure 3 shows that INDEX subjects spent a low of $\$ 0.61$ per week to a high of $\$ 12.56$ per week in the Flat-Rate Buy-Out experiment, with 50 percent of the subjects spending less than $\$ 4$ per week and 20 percent spending more than $\$ 8$ per week.

It becomes obvious that the disparities in expenditures are not simply due to environmental or seasonal effects, when the subjects' weekly mean expenditures in different experiments are analyzed. The disparities are rather an inherent characteristic of individual demand. Figure 4 shows this effect. The mean weekly expenditure of $48 \%$ of the INDEX subjects in the two Minute Pricing experiments, and Byte Pricing experiments varies only in a range of $\$ 2$. Considering that subjects were facing widely varying prices over the course of the three disparate experiments, this fact gives clear evidence that a significant percentage of subjects have an exact idea of how much they are willing to spend for Internet service in a given time period. Another $24 \%$ of our subjects also set relatively tight constraints on their Internet budget, allowing for a maximum variation of $\$ 4$. Only the remaining $26 \%$ displayed a wider variation in their expenditure distribution.

\section{Over-Usage under Flat-Rate Pricing Plans}

INDEX data also gives an estimate of the magnitude of increase in usage under flat-rate plans compared with usage under usage-based pricing plans. Figure 5 


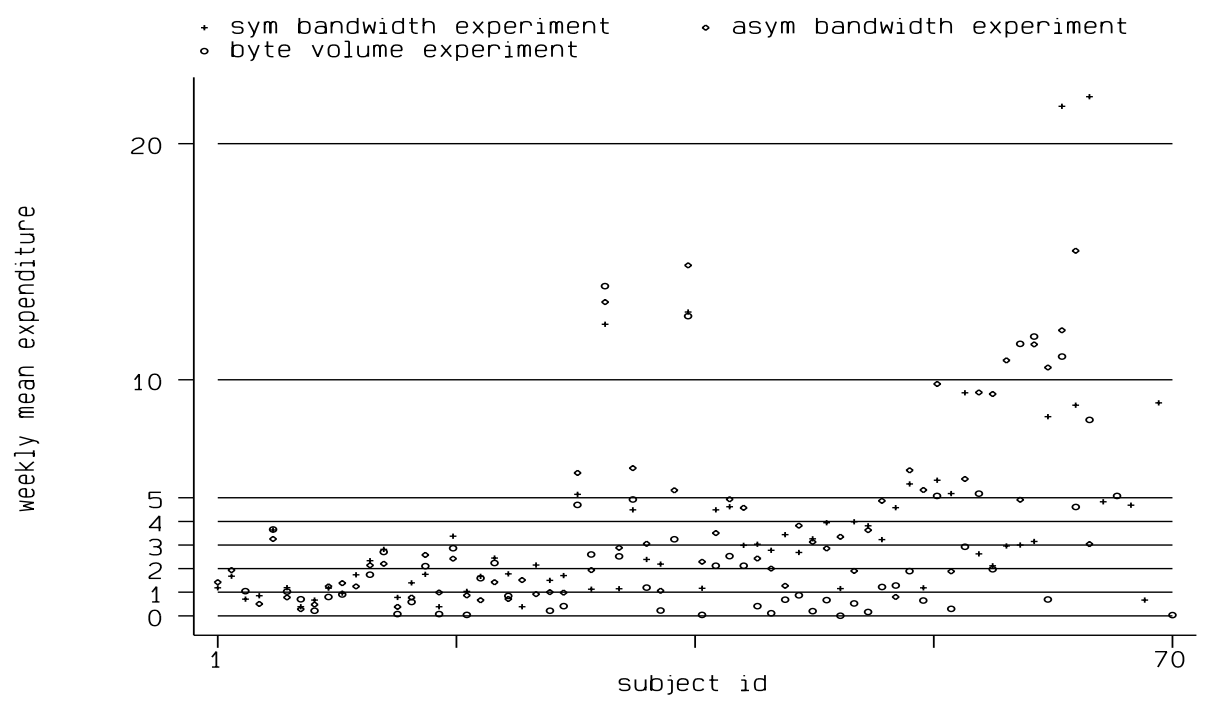

Fig. 4. Budget

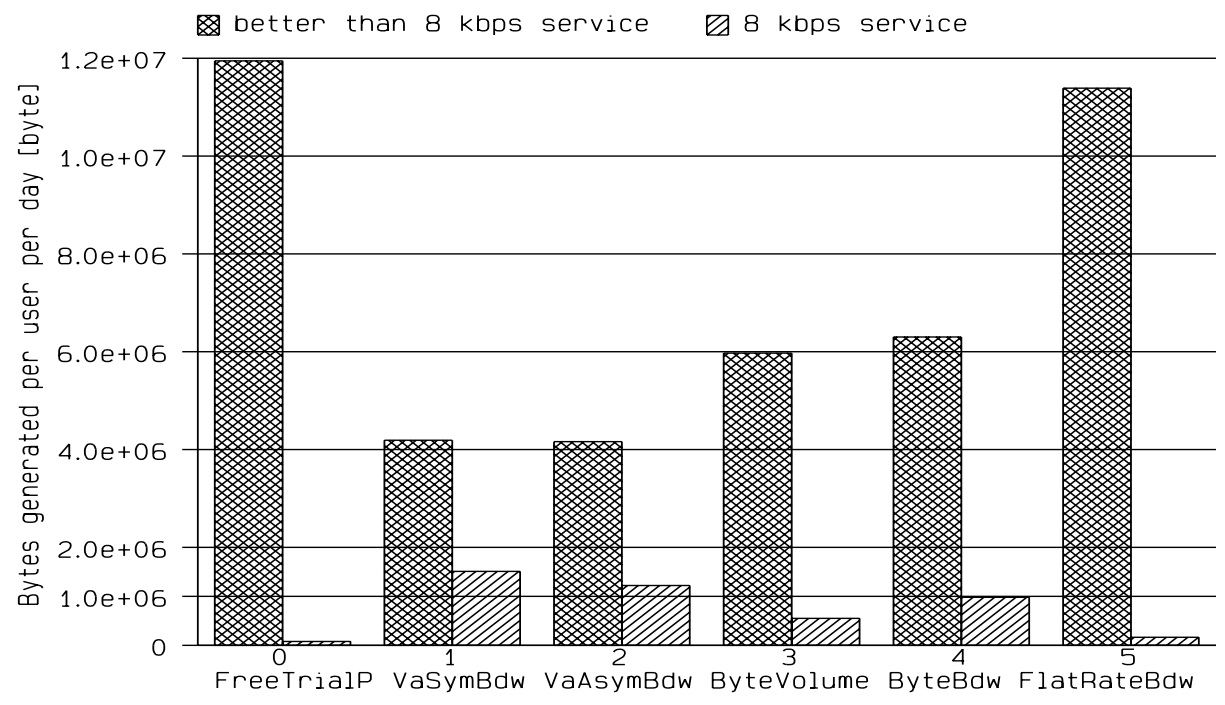

Fig. 5. Average Number of Bytes Transmitted

shows the average number of bytes transmitted in the free trial weeks and in five different experiments (the two Minute Pricing experiments, the Byte Pricing experiment, the Minute-Byte Pricing experiment, and the Flat-Rate Buy-out Option experiment). During the free trial periods (which is equivalent to flat-rate pricing plans at $128 \mathrm{kbps}$ ), the number of bytes transmitted are significantly higher than the bytes transmitted in any of the four purely usagebased pricing experiments. The bytes transmitted by subjects during the free weeks is twice the number of bytes transmitted in the Byte Pricing experiment and the Minute-Byte Pricing experiment, and almost three times the byte volume transmitted in the Minute Pricing experiments. 


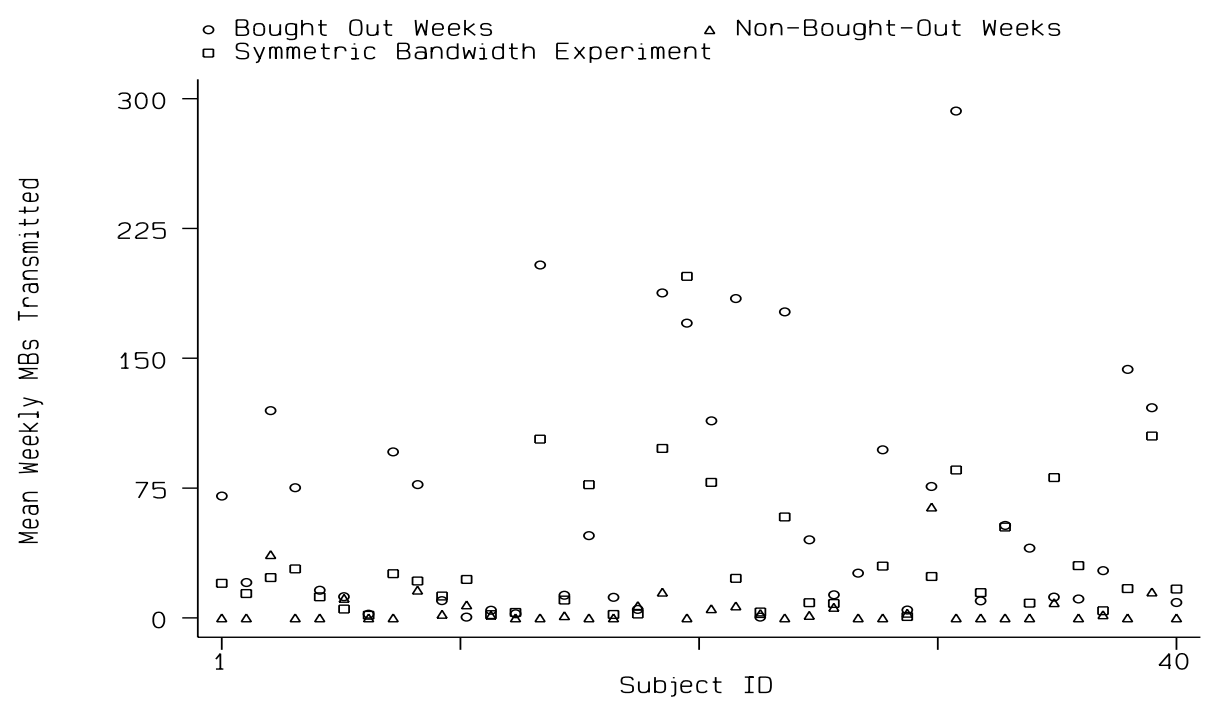

Fig. 6. Comparison of Usage by Subject Between the Bought-Out, the Non Bought-Out Weeks in the Flat-Rate Buy-Out Option Experiment, and the usage in the Symmetric Bandwidth Experiment

When a bandwidth was bought out in the Flat-Rate Buy-Out Option experiment (i.e., the user had unlimited access at the bought-out bandwidth), the mean number of bytes transmitted per user week was 75 mbyte. This is a significant change, compared with a mean of 8.86 mbyte per user week in the weeks in which no bandwidth was bought out. This also explains why the mean daily usage of subjects in the Flat-Rate Buy-Out Option experiment is almost as high as the usage in the free weeks. The usage is strongly influenced by the flat-rated part of the pricing plan.

Interestingly, large usage differences exist even for the same subject in the weeks in which the subject had flat-rate, unlimited access compared with the weeks in which the subject paid purely usage-based charges.

In Figure 6, all of the 40 subjects are arrayed on the x-axis and the triangles represent each subject's mean weekly number of bytes transmitted in their non-bought-out weeks in the Flat-Rate Buy-Out Option experiment. Note, even though the triangles appear to be zero, they are all in fact positive, though small, numbers. The circles represent the same subject's mean weekly bytes transmitted in their bought-out weeks in the Flat-Rate Buy-Out Option experiment. From the figure, we can see that for all but two subjects, mean weekly bytes transmitted in the bought-out weeks is significantly higher than mean weekly bytes transmitted in the non-bought-out weeks. In fact, almost 58 percent of the INDEX subjects transmitted more than three times as much volume in their bought-out weeks compared with their non-bought-out weeks. From Figure 6, we can also see that most subject's mean weekly transmitted number of bytes in the Symmetric Bandwidth experiment lies below their 


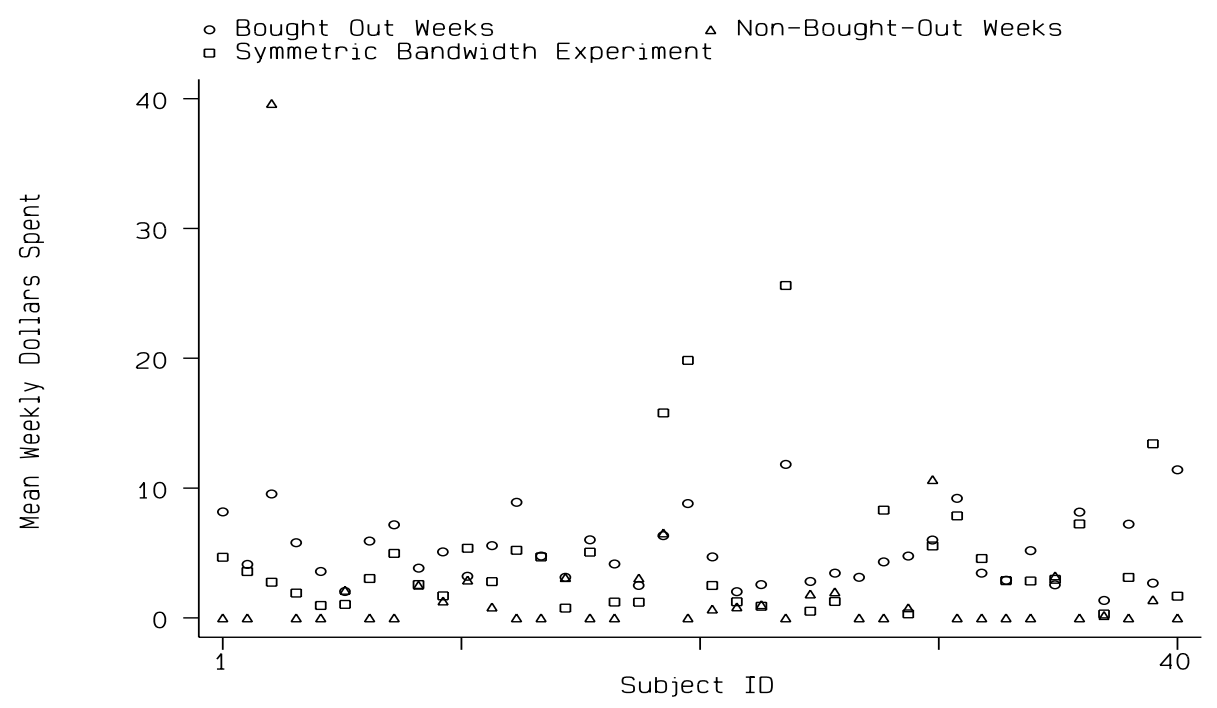

Fig. 7. Comparison of Expenditures Between the Flat-Rate Buy-Out Experiment and the Symmetric Bandwidth Experiment

mean weekly bytes transmitted in the bought-out weeks. The INDEX findings are that subjects transmit a significantly greater number of bytes under flatrate, unlimited access pricing plans compared with usage-based pricing plans.

This findings are also confirmed by Figure 7, which compares the subjects' expenditures under the Symmetric Bandwidth experiment and the Flat-Rate Buy-Out Option experiment. From this figure, we see that INDEX subjects spent more money per week during the bought-out weeks of the Flat-Rate Buy-Out Option experiment than during either the Symmetric Bandwidth experiment or the non-bought-out weeks of the Flat-Rate Buy-Out Option experiment. However, the percentage increase in each subject's mean weekly spending is smaller than the percentage increase in each subject's bytes transmitted when going from the Symmetric Bandwidth experiment to the boughtout weeks of the Flat-Rate Buy-Out Option experiment.

\section{Attractiveness of Flat-Rate Pricing Plans}

The majority of the INDEX subjects selected a flat-rate, unlimited-access pricing plan. About 85 percent of the subjects bought out a bandwidth in at least half of their weeks in the Flat-Rate Buy-Out Option experiment. 52.5 percent of the INDEX subjects bought out a bandwidth in every one of their weeks in the experiment. The mean weekly fixed charge paid by the subjects in the weeks, in which a bandwidth was bought out, was $\$ 5.25$. This is approximately equal to the monthly flat-rate of $\$ 21$ charged by major ISPs for Internet access. 


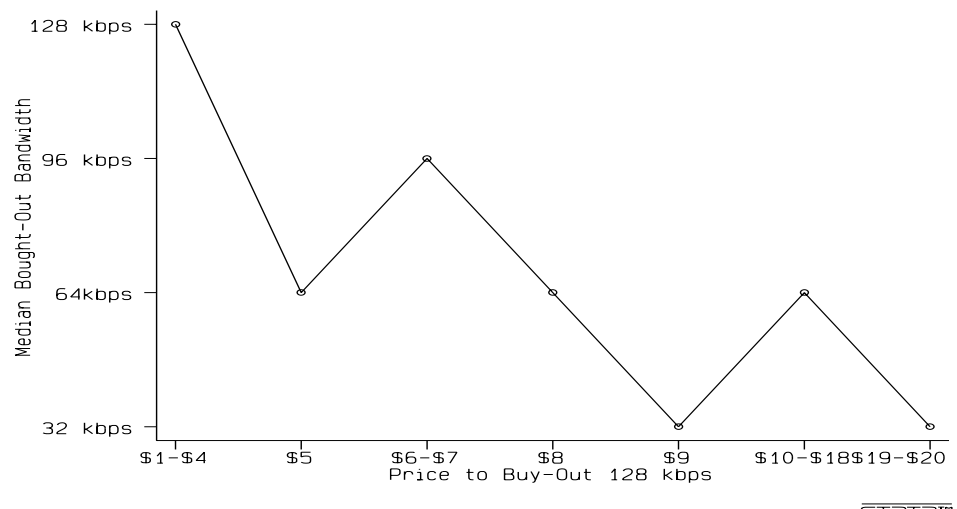

Fig. 8. Median Bought-Out Bandwidths Fall as the Flat-Rate Buy-Out Prices for 128 kbps Rise

When the price for buying out the bandwidths rose, the INDEX subjects had two options. On the one hand, they could continue buying out the same bandwidths as they had previously, thereby staying at their previously selected bandwidth but paying a higher flat fee. On the other hand, alternatively, they could select a lower bandwidth, keeping or reducing the expenditures. Many subjects chose to buy out a lower bandwidth and lower their flat fee as the buy-out prices increased. For example, as shown in Figure 8, when the weekly buy-out price for $128 \mathrm{kbps}$ was between $\$ 1$ and $\$ 4$, the median bandwidth that was bought out was $128 \mathrm{kbps}$, which meant that almost everyone who chose the flat-rate option chose to buy out the $128 \mathrm{kbps}$ service. However, when the weekly buy-out price for $128 \mathrm{kbps}$ rose to $\$ 6$, the median boughtout bandwidth dropped to $96 \mathrm{kbps}$. That means that one half of the INDEX subjects who chose the flat-rate option bought out $96 \mathrm{kbps}$ or an even lower bandwidth for which they paid a flat-rate of $\$ 4.50$ (for $96 \mathrm{kbps}$ ) or less (for bandwidths lower than $96 \mathrm{kbps}$ ). The other half of the subjects who chose the flat-rate option chose to buy out $128 \mathrm{kbps}$ for which they paid the full $\$ 6$. Under a weekly buy-out price of $\$ 8$, the median bandwidth that was bought out had dropped to $64 \mathrm{kbps}$ [Chu 1999].

This behavior is consistent with our earlier findings that many subjects appears to have a narrow range of expenditures across the different experiments (Figure 4). This behavior also suggests that the subjects cared about having a flat-rate option for basic access. But, most of them did not appear to care as much about which particular bandwidth they were able to use for access under the flat-rate option. It may be because they were always able to access a higher bandwidth on demand at any time in the future.

Additional evidence that subjects value flat-rate pricing for basic access is the amount of money they are willing to pay. In particular, many subjects are paying a premium to buy out a bandwidth for the week. The premium is defined as the difference between the subject's total expenditures for his usage 


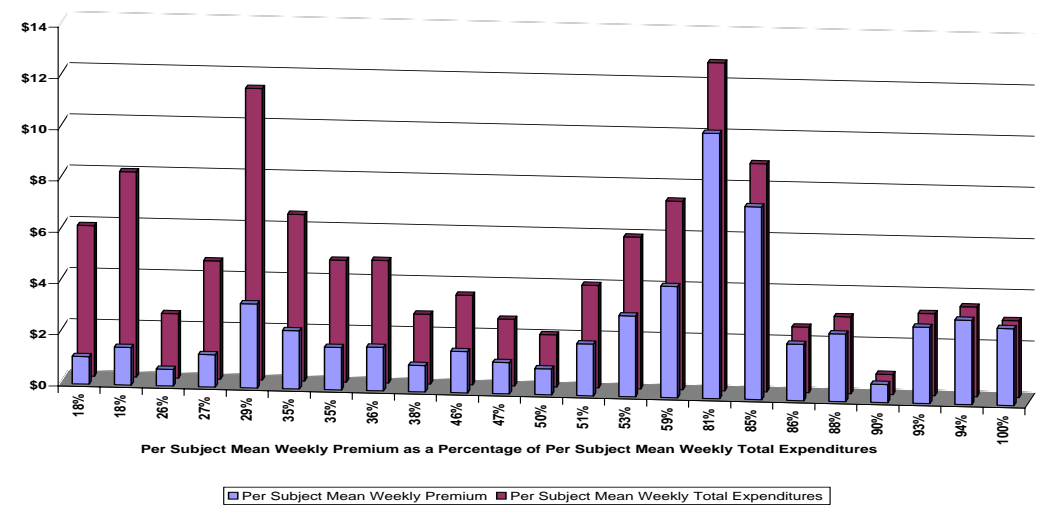

Fig. 9. Individual-Specific Values of Mean Weekly Premiums compared with Individual-Specific Values of Mean Weekly Total Expenditures

that week minus what the subject's total expenditures would have been under the cost-minimizing choice. To compute each subject's cost-minimizing choice for a particular week, we took the subject's chosen vector of connect times that week at each bandwidth. Then, we computed the cost of that vector at every possible buy-out choice. This method of computing the minimum charge for a particular choice tends to overstate the number of cost-minimizing choices since a subject is likely to use more connect time when the marginal price is zero than when the price is positive.

Using this conservative estimate of the cost-minimizing choice, we find that in 23 percent of the weeks, in which a bandwidth was bought out, the subject's bandwidth buy-out decision was not cost minimizing. The premium as a percentage of the mean total weekly expenditures ranged from a low of 0.18 percent to a high of 100 percent, with a median of 50 percent. In monetary terms, the premiums ranged from a low of $\$ 0.65$ to a high of $\$ 9.21$, with a median of $\$ 2.02$. Figure 9 illustrates these results even in more detail, showing the subject-specific mean premium for the weeks that were bought out and were not cost minimizing. 23 subjects had non cost-minimizing choices.

\section{Demand for Flexibility}

In all experiments, INDEX subjects made use of a wide range of bandwidths, showing that their demand for network service was variable over time. Almost every subject purchased high quality service at least once.

Figure 10 shows a histogram, displaying the number of different QoS choices that subjects made over the entire duration of the Symmetric Bandwidth experiment. $62.5 \%$ of the subject population made use of the entire range of 


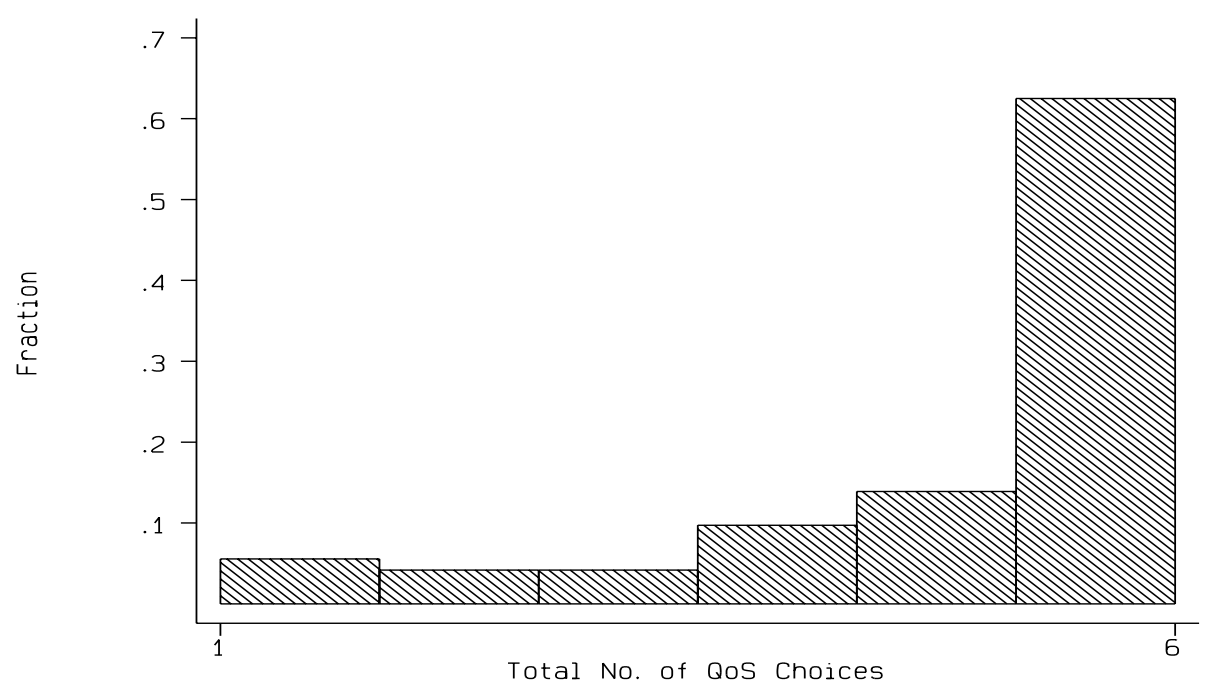

Fig. 10. QoS Choices by Subject within the Per-Minute and Per-Byte Experiment

options (8 kbps to $128 \mathrm{kbps}$ ). $75 \%$ used at least five different bandwidths.

In the Flat-Rate Buy-Out Option experiment, 82.5 percent of INDEX subjects, who had paid a flat-rate to attain unlimited access at a particular bandwidth for the week, continued to use higher, non-bought-out bandwidths on occasion even though they were charged per-minute prices for using the nonbought-out bandwidths. Another 10 percent of the subjects bought-out the $128 \mathrm{kbps}$ service in every week and had unlimited access to the highest available bandwidth. Hence only 7.5 percent of the subjects did not use higher, non-bought-out bandwidths on demand.

Figure 11 shows the distribution of subjects' usage of multiple bandwidths higher than their bought-out bandwidth. As shown in the top left graph of Figure 11, approximately $50 \%$ of the subjects, who bought out $16 \mathrm{kbps}$ used one additional bandwidth higher than $16 \mathrm{kbps}$, even though they had to pay usage charges to use that higher bandwidth. Approximately $40 \%$ of these subjects actually used all three additional higher bandwidths available when they bought out $16 \mathrm{kbps}$. The top right graph of Figure 11 shows that approximately $50 \%$ of the subjects who bought out $32 \mathrm{kbps}$ used one additional bandwidth higher than $32 \mathrm{kbps}$ and paid usage charges to use that higher bandwidth. Almost $25 \%$ of them used two additional bandwidths higher than 32 kbps. The bottom left graph of Figure 11 illustrates that almost $48 \%$ of the subjects who bought out $64 \mathrm{kbps}$ used one additional bandwidth higher than 64 kbps and almost $25 \%$ of them used both additional higher bandwidths available. Finally, as shown in the bottom right graph of Figure 11 almost $64 \%$ of the subjects who bought out $96 \mathrm{kbps}$ used $128 \mathrm{kbps}$ during the week and paid a usage-based charge. 

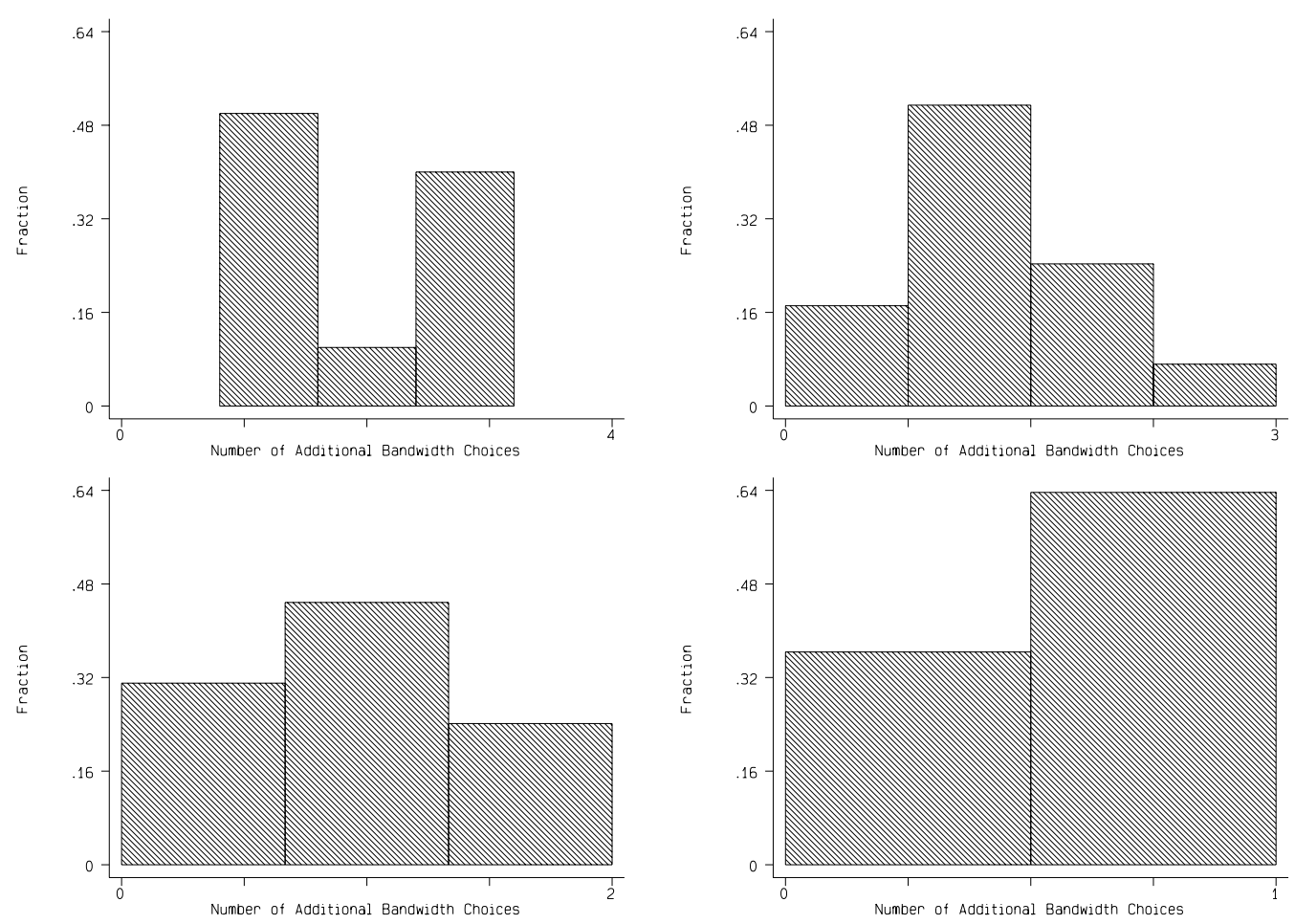

Fig. 11. QoS Choices by Subjects who Bought Out 16/32/64/96 kbps

These results provide support for the contention that subjects want the ability to use higher, non-bought-out bandwidths on occasions when they have the need to do so.

\section{The Proposed New Pricing Plan}

The results we presented in this paper showed that there is demand for more flexible pricing plans than the currently predominant flat-rate and per-minute pricing plans.

From the user's perspective, two issues are important with regard to pricing plans for Internet access services: first, flexibility in choosing QoS for Internet access on demand and, second, convenience of not being bothered with a constantly ticking meter calculating the usage-based charges for accessing the Internet.

The results we presented showed that INDEX subjects appreciate the flexibility of requesting higher service quality on demand, even if they had to pay a per-minute rate for the service. $75 \%$ of the subjects used the entire range of options given to them. However, the convenience of not thinking about ticking 
meters is also very important to the user. As the analysis showed, subjects are willing to pay a premium for not being charged under a per-minute pricing plan.

The pricing plan that we are proposing combines these user-appreciated features. Under the proposed pricing plan, the user chooses a flat-rate basic service, which provides access to the Internet at a certain basic rate. This is a rough segmentation by tiered services. In addition to this, the ISPs offers all customers the ability to request higher bandwidth on demand. This service will be charged based on usage, which might be per-byte, per-minute, or a combination of the two.

From the ISP's perspective, this kind of pricing plan is also very attractive, since it deals with the issue of over-usage under a flat-rate service (which would be very critical for broadband access). Deploying such a pricing plan, the ISP can attractively offer broadband access to the group of heavy Internet users without limiting the Internet access service to certain kind of applications. For example, @Home restricted the use of streaming media to their customers in 1999.

In addition to that, this kind of pricing plan enables the ISPs to get additional revenues beside the revenues they would get from a purely flat-rate service. ISPs could meet the current demand of their users at any time. For example, if users, who chose a basic service, require better quality service now and then, the ISP can provide them with such a service and charge them based on their usage under this pricing plan. The ISP gets the surplus the user is willing to pay in these situations. This statement is also supported by our data. INDEX received revenues of only 7.75 cents per mbyte in the bought-out weeks compared with revenues of 30.41 cents per mbyte in the non-bought-out weeks. (Note: the subjects' mean weekly total expenditures was higher for the bought-out weeks.)

Since this pricing plan meets the needs of users and the requirements of ISPs, it might be the preferred pricing plan in a more competitive Internet service provider market.

\section{Conclusion}

The overall conclusion we can draw is that users and ISPs prefer a pricing plan, in which users pay a flat-rate charge for basic service and a usage-based charge when accessing a higher service quality that they can utilize on demand. In order to underpin this conclusion, we presented analysis results, based on data of the INternet Demand EXperiment project (INDEX). We showed that 
users are willing to pay a premium to use a flat-rate Internet access service and are utilizing better service qualities on demand. We also illustrated that such a pricing plan prevents over-usage of resources because of its usage-based component.

\section{References}

[1] J. Altmann, B. Rupp, and P. Varaiya, 1999a, "The Case for Quality of Service on Demand," ISQE'99, Workshop on Internet Service Quality Economics, in press, Cambridge, MA, USA, December 1999.

[2] J. Altmann, B. Rupp, and P. Varaiya, 1999b, "Internet Demand under Different Pricing Schemes," EC'99, ACM Conference on Electronic Commerce (SIGecomm), Denver, Colorado, USA, November 1999.

[3] K. Chu, 1999, "User Reactions to Flat-Rate Options under Time Charges with Differentiated Quality of Access: Preliminary Results from INDEX," ISQE'99, Workshop on Internet Service Quality Economics, in press, Cambridge, MA, USA, December 1999.

[4] A. Hoag, 1997, "Speed and the Internet: The Effects of High Speed Access on Household Usage," Proceedings of the 25th Telecommunications Policy Research Conference, section IX, 1997.

[5] S. Shenker, D. Clark, D. Estrin, Shai Herzog 1996, "Pricing in Computer Networks: Reshaping the Research Agenda," Telecommunications Policy, vol. 20(3), 1996.

[6] U.S. Census Bureau 1999, Educational Attainment Table 1, March 1998 (table posted on the web at www.census.gov), 1999. 